\title{
Methodological Strategies for Resilience Research in Lesbians, Gays and Bisexuals (LGBs): Integrative Review of the Literature
}

\author{
Aline Nogueira de Lira*, \\ Orcid.org/0000-0002-7503-3742 \\ Normanda Araujo de Morais ${ }^{1}$ \\ Orcid.org/0000-0003-3156-4688
}

${ }^{1}$ Universidade de Fortaleza, Fortaleza, CE, Brasil

\begin{abstract}
Through the integrative literature review, this article aimed to analyze the methodological strategies for resilience research in empirical studies with lesbians, gays and bisexuals (LGBs). The searches were carried out at SciELO, PePSIC, LILACS, Index Psi, PsycINFO e PUBMED, until the year 2015. In order to guide and systematize the undergoing of the review, the guidelines laid down in the Protocol PRISMA were followed and after consideration of the inclusion and exclusion criteria, 31 articles were identified and analyzed in full. Studies focused only on variables, with focus only on people and including both variables and people were identified. Despite the conceptual and methodological advances about the resilience and the LGB population, some controversies are still observed, compromising the quality of evaluation of this construct. The measuring and/or understanding of resilience is not a simplistic task. It passes through observation and dialogue among risk factors, protection factors and positive adaptation factors, as well as dialectically relating to different levels and contexts involved such as individual, family, community and culture. The inconsistency in the operationalization of these factors can impair the generalization and the understanding of the empirical results.
\end{abstract}

Keywords: Resilience, LGB, method, integrative review.

\section{Estratégias Metodológicas de Investigação da Resiliência em Lésbicas, Gays e Bissexuais (LGBs): Revisão Integrativa de Literatura}

\section{Resumo}

Pela revisão integrativa de literatura, este artigo buscou analisar as estratégias metodológicas para investigação da resiliência nos estudos empíricos com pessoas lésbicas, gays e bissexuais (LGBs). As buscas foram realizadas nas bases SciELO, PePSIC, LILACS, Index Psi, PsycINFO e PUBMED, até

* Mailing address: Universidade de Fortaleza, Avenida Washington Soares, 1321, Edson Queiroz, Fortaleza, CE, Brasil 60811 905. Caixa-postal: 1258. E-mail: aline.lira09@hotmail.com and normandaaraujo@gmail.com Support: Coordenação de Aperfeiçoamento de Pessoal de Nível Superior (CAPES); Conselho Nacional de Desenvolvimento Científico e Tecnológico (CNPq). 
o ano de 2015. Para nortear e sistematizar a execução da revisão seguiu-se as diretrizes enunciadas no protocolo PRISMA e após a consideração dos critérios de inclusão e exclusão, foram identificados e analisados na íntegra 31 artigos. Identificou-se estudos com foco nas variáveis, com foco nas pessoas e os que incluem simultaneamente as variáveis e as pessoas. Apesar dos avanços conceituais e metodológicos acerca da resiliência e a população LGB, algumas controvérsias ainda são observadas, comprometendo a qualidade da avaliação desse construto. A medição e/ou compreensão da resiliência não é uma tarefa simplista, mas passa pela observação e diálogo entre os fatores de risco, de proteção e de adaptação positiva, além de envolver dialeticamente os diferentes níveis e contextos envolvidos: individual, familiar, comunitário e cultural. A inconsistência na operacionalização desses fatores pode prejudicar a generalização e a compreensão dos resultados empíricos.

Palavras-chave: Resiliência, LGB, método, revisão integrativa.

\section{Estrategias Metodológicas de Investigación en Resiliencia en Lesbianas, Gays y Bisexuales (LGBs): Revisión Integrativa de la Literatura}

\section{Resumen}

Por la revisión integrativa de literatura, este artículo analizó las estrategias metodológicas para la investigación de la resiliencia en los estudios empíricos con lesbianas, gays y bisexuales (LGBs). La búsqueda fue realizada en las bases SciELO, PePSIC, LIIACS, Index Psi, PscycINFO y PUBMED, hasta el año de 2015. Para sistematiza la revisión de literatura, seguimos las directrices enunciadas en el protocolo PRISMA y luego de la consideración de los criterios de inclusión y exclusión, fueron identificados y analizados íntegramente 31 artículos. Se identificaron estudios con foco en las variables, en las personas y aquellos que incluyen a la vez las variables y las personas. A pesar de los avances conceptuales y metodológicos acerca de la resiliencia y de la población LGB, aspectos controversiales fueron observados, lo que comprometió la calidad de la evaluación del constructo. La medición y/o la comprensión de la resiliencia no es una tarea sencilla, pero pasa por la evaluación y el diálogo entre los factores de riesgo, de protección y de adaptación positiva, además de envolver dialécticamente diferentes niveles y contextos: individual, familiar, comunitario y cultural. La inconsistencia en la operacionalización de estos factores puede perjudicar la generalización y la comprensión de los resultados empíricos. Palabras-clave: Resiliencia; LGB; método, revisión integrativa.

Palabras clave: Resiliencia, LGB, método, revisión integrativa.

Increasing attention has been given to the resilience processes experienced by lesbians, gays and bisexuals (LGBs), especially in the international setting. In addition to the context of risk and vulnerabilities that sexual minorities face daily in their social and family spaces, mainly due to homophobic prejudice, recent studies have shown the coping and overcoming capacity of this population, emphasizing the individual, family and community strategies that enable them to prosper and demonstrate good developmental results (Lira \& Morais, 2017; Lyons, 2015). Thus, not all LGB individuals suc- cumb to adversity. Many of them, using resilience processes, are strengthened by stress and excel with even more resources to carry out their life projects.

Resilience is conceptualized as the dynamic and procedural ability to successfully manage and adapt to the adverse circumstances of life (Luthar, Cicchetti, \& Becker, 2000). From this definition, two distinct dimensions make up this construct: (1) the presence of significant situations and / or contexts of adversity, identified from the observation of risk factors; (2) the understanding of positive adaptation, that is, the 
existence of a set of factors and systems that contribute to a dynamic and interactive process that increases the chance of resisting adversity (Luthar et al., 2000; Masten \& Monn, 2015).

Although there is a relative increase in LGB population resilience literature, these studies are found in the early stages and their definition and measurement / understanding still represent a challenge (Colpitts \& Gahagan, 2016; Lyons, 2015). First, the challenges arise from the lack of homogeneity in the definition of resilience, which is sometimes defined as a trait, focused above all on individual characteristics; and, sometimes, as a dynamic process, which involves the complex relationship between risk factors, protection factors and positive adaptation. This study, therefore, starts from the latter concept, in which resilience is not restricted to internal resources or personal qualities, but involves the interaction of individual and contextual aspects. The second difficulty concerns precisely the assessment of risk-setting criteria, protection resources, and how well a person responds positively to adverse events, which may compromise the intelligibility and operationalization of resilience (Masten, 2015).

Resilience research has adopted two main analytical research strategies: variable-focused studies and people-centered studies (Masten, 2015). The first approach uses multivariate statistical analysis to identify patterns, measuring personal, interpersonal, and contextual characteristics. In addition, it seeks to explore the links between risk, protection and adaptive patterns, and also establishes relationships between predictive variables, mediator variables, moderator variables and adaptive outcomes.

The second analytical approach, with a predominance in qualitative studies, uses the individual as the main object of investigation and seeks to understand in depth the meanings that people attribute to their realities of life. There is also the capturing of relational and contextual patterns, which are linked to the risks and ways of overcoming that involve people's life trajectories. Person-centered studies can also be quantitative, especially when, used in a deductive way, they involve the classification of individuals in situations of risk and seek to compare them with different adaptation profiles. Both approaches, focused on the variable and the person, present strengths and weaknesses, so that some scholars choose to include the two operational models in the same research (eg, Kubicek, McNeeley, Holloway, Weiss, \& Kipke, 2013; Rodríguez \& Calle, 2013).

As a way of increasing the knowledge about the evaluation of resilience, an integrative review of the literature was carried out with the general objective of analyzing the methodological strategies for investigating resilience in empirical studies with LGB people. To reach this objective the following questions were asked: How has resilience been investigated methodologically in the empirical studies with LGB individuals? Specifically, what analytical models of resilience research have been used? And what variables, instruments, and methods of data analysis are most commonly used to measure and understand the phenomenon of resilience?

One of the central questions in research on resilience in the LGB population is the evaluation of how this construct can be investigated methodologically, that is, measured (quantitatively) and understood (qualitatively). In this sense, it is believed that this integrative literature review can contribute to the two fields of knowledge in question: on resilience and on the development of the LGBs population. By rigorously synthesizing and discussing the methodological strategies of resilience models and sexual minorities, one can collaborate in the theoretical-methodological alignment of this field of investigation and increasingly strengthen the intelligibility of this construct. In addition, the construct of resilience can be a rich conceptual model for assessing health and indicating strategies for developmental intervention in the lives of the LGB population (Colpitts \& Gahagan, 2016).

\section{Method}

It is an integrative review of the literature and to guide and systematize the implementation of the review the guidelines stated in the PRISMA Protocol (Preferred Reporting Items 
for Systematic Reviews and Meta-Analysis; Liberati et al., 2009) were followed.

Database and procedures for data collection: The databases selected were PUBMED, PsycINFO, Scientific Electronic Library Online (SciELO), Electronic Periodicals of Psychology (PePSIC), Latin American and Caribbean Literature in Health Sciences (LILACS) and IndexPsi, so as to study both national and international literature, and include both health studies and psychology studies, and thus, point out the main trends and results of the subject investigated. The bibliographic collection was first performed in August 2015 and later, in December of the same year, with the inclusion of new articles. The search descriptors in Portuguese with Boolean operators and trick processes were: (resilien\$) AND (homosex\$ OR lesbi\$ OR gay\$ OR bissex\$ OR LGBT OR same sex) and the respective terms in English (resilien*) AND (homosex* OR lesb* OR gay* OR bisex* OR LGBT OR same-sex). Although the study did not aim to investigate the methodological strategies of resilience with the trans (transgender, transsexual) population, the term LGBT was included because it is an expression widely used in the academic environment and would therefore include a larger number of studies with sexual and gender minorities.

Selection of studies: For inclusion the studies would have to: (1) be empirical - quantitative, qualitative or mixed; (2) aim to investigate the resilience processes in the LGB population. There was no restriction in the publication period, given the initial stage of resilience research and sexual minorities. Duplicate articles, theoretical articles, book chapters, systematic, narrative, and integrative literature reviews, news, technical documents, editorials, comments, dissertations and thesis were excluded. Studies that were not intended as a study on resilience itself, even though they did explore some concepts related to resilience (risk, protection, positive adaptation), were also excluded. Thereafter, the titles and abstracts were examined, in accordance with the established inclusion and exclusion criteria. After this first selection, all articles were retrieved in the complete version and then submitted to the evaluation of two independent judges - two graduate students (both members of the research group of which the authors of this article are part), following the protocol entitled Relevance Test (Azevedo, 2010). This test consists of four items referring to the quality of the article by considering the following criteria: clarity of the research problem; relation of the study objective to the question being investigated; clarity of methodology and achievement of objectives; and compatibility between results and methodology. A further item was included in the protocol of whether the study aimed to study resilience and the LGB population. The exclusions were clarified by the judges and the divergences resolved in a common consensus. Once the articles that composed the analysis corpus of this review were selected, they were analyzed and their data were stored in an Excel worksheet. Subsequently, the classification process by categories began, taking into account the general objective of the study.

Analysis and Data Synthesis: For data analysis and a better understanding of the phenomenon investigated, the studies were categorized following the analytical approaches of resilience proposed by Masten (2015): (1) Studies focused on the variable; (2) Studies focusing on the person and; (3) Studies focused on the variable and the person simultaneously. As the main objective of this study is about the methodological strategies for the operationalization of resilience, in each of the categories of analysis the delineation, the main variables (when quantitative), the main instruments (when qualitative) and the data analysis used for resilience research were observed and discussed.

\section{Results and Discussion}

The initial search in the electronic databases located 172 studies, which were identified only in the international databases: PUBMED $(n=127)$ and PsycINFO $(n=45)$. After reading the titles and abstracts, the inclusion and exclusion criteria were applied, arriving at the following data: 
comments and technical reports $(n=9)$; studies that did not problematize the theme "resilience and the LGB population" ( $n=38)$, theoretical and revision studies $(n=18)$. Subsequent to this first selection, we obtained a number of 107 studies, of which all the texts were completely retrieved. These articles were sent to the judges and submitted to the protocol entitled Relevance Test (Azevedo, 2010). From this analysis there was a discordance rate of approximately $6 \%(n$ $=2$ ) among the judges, which they clarified and resolved in a consensus among themselves. The disagreement was mainly in the understanding whether or not the article had resilience as its focus. Thus, 76 articles were excluded. Among the main reasons for exclusion, after examination, the following stand out: studies that did not meet the objective of the review, that is, they did not aim to investigate resilience in the context of sexual minorities (gays, lesbians and bisexuals); articles that evaluated only some of the indicators of resilience (well-being, quality of life, risk factors, protection factors etc.) but not resilience per se; studies that analyzed resilience exclusively in the context of gender (transgender) minorities. Finally, 31 studies were included that made up the body of analysis of this study, being: PUBMED $(n=22)$ and PsycINFO $(n=9)$. No articles about resilience and sexual minorities were found in the other databases, which indicates a lack of studies related to this topic in the national and Latin American scenario. The complete references of the studies included in this integrative review are highlighted with an asterisk in the References section.

\section{Studies Focused on the Variable}

In the variable-focused studies, it was possible to identify the relationships between risk variables, protection variables and adaptation/ psychosocial adjustment variables specific to the LGB population, as well as to explore patterns of variance between individual characteristics (experiences, interrelationships and context), which can explain different developmental results. Table 1 presents a description of the design of the variables used in each study, seperated into independent variables, moderators, mediators and dependent variables (outcomes), as well as methods of data analysis (models of correlation, regression, mediation and moderation).

A total of 19 articles were found, published between 2003 and 2015, of which 9 were published in 2015. Cross-sectional studies $(n=16)$ were prominent, although 3 were longitudinal.

\section{Variables for Assessing Resilience}

Several studies analyzed here have assumed resilience as a process, and to measure it they used multidimensional quantitative measurements associated with the interaction between risk factors and protective factors (independent variables) and indicators of positive adaptation (dependent variables). The risk variable often used in the studies of this review and that is significantly associated with the developmental outcomes of sexual minorities refers to homophobia, whether external (homophobic victimization, heterosexism) and / or internal (internalized homophobia; e.g., Herrick et al., 2013; Mereish \& Poteat, 2015). It was also observed that aspects such as family rejection, especially among young and elder LGB (e.g., Zimmerman et al., 2015), stigma awareness (Figueroa \& Zorcolla, 2015), concealment of sexual orientation (Livingston et al., 2015), racism (Peterson et al., 2014) and lack of socioeconomic resources (Fredriksen-Goldsen et al., 2015) were also associated with poor psychosocial adjustment. See variables used in each study in Table 1.

The main variables related to protection factors that have the role of favoring resilience processes among LGB people, are referred to as internal (personal) and external (contextual) protective resources. In regard to the internal protection resources, it were identified, for example: emotional openness, hope, optimism (Kwon, 2013), positive sense regarding sexual orientation (Fredriksen-Goldsen et al., 2015; Kosciw et al., 2015), and faith / spirituality (Walker \& Longmire-Avital, 2013), among others (see Table 1). In turn, external protection fac- 
Table 1

Characterization of the Quantitative Studies of Resilience and the LGB Population by Year of Publication

\begin{tabular}{|c|c|c|c|c|c|}
\hline \multirow[t]{2}{*}{ Studies } & \multirow[t]{2}{*}{ Study Design } & \multicolumn{3}{|c|}{ Variables for evaluation of Resilience } & \multirow{2}{*}{$\begin{array}{c}\text { Data analysis } \\
\text { models }\end{array}$} \\
\hline & & $\begin{array}{c}\text { Independent } \\
\text { Variables }\end{array}$ & $\begin{array}{c}\text { Dependent } \\
\text { variables }\end{array}$ & $\begin{array}{l}\text { Variable } \\
\text { Mediators / } \\
\text { Moderators }\end{array}$ & \\
\hline $\begin{array}{c}\text { Bruce, } \\
\text { Harper, \& } \\
\text { Bauermeister } \\
(2015)\end{array}$ & Cross-sectional & $\begin{array}{l}\text { Stigma experience; } \\
\text { Stress due to concealment } \\
\text { of sexual orientation; } \\
\text { Social Support }\end{array}$ & Depression & $\begin{array}{c}\text { Internalized } \\
\text { Homophobia; } \\
\text { Development } \\
\text { of positive } \\
\text { identity } \\
\text { (indicator of } \\
\text { resilience) }\end{array}$ & Mediation \\
\hline $\begin{array}{c}\text { Buttram, } \\
\text { Surratt, \& } \\
\text { Kurtz (2014) }\end{array}$ & Cross-sectional & $\begin{array}{c}\text { Lack of housing; Severe } \\
\text { mental stress; Substance abuse; } \\
\text { Victimization; } \\
\text { HIV risk; Education; } \\
\text { Health coverage; } \\
\text { Access to transport }\end{array}$ & $\begin{array}{c}\text { Personal } \\
\text { mastery } \\
\text { (Resilience) }\end{array}$ & --------- & Regression \\
\hline
\end{tabular}

Figueroa Cross-sectional \& Zoccola

(2015)

Fredriksen- Cross-sectional Goldsen,

Kim, Shiu,

Goldsen, \&

Emlet (2015)
Kosciw, Cross-sectional

Palmer, \&

Kull (2015)

Mason, Cross-sectional Lewis,

Winstead, \& Derlega

(2015)

\section{Harassment, discrimination and heterosexist rejection; Stigma Awareness}

Victimization and discrimination throughout life; Identity management features (positive sense of identity, disclosure of identity, time of disclosure);

Social resources (partners or married, size of social network, religious or spiritual activities, social support, connectivity); Health promotion behaviors; (physical activity, leisure activity, routine check-up, non-use of substance);

Socioeconomic resources (income, employment, and education).

Opening of sexual orientation; Victimization

\footnotetext{
Harassment, rejection and heterosexist discrimination; Internalized homophobia; Social restrictions
}

Physical health; mental health

Psychological Moderation (depression, anxiety and somatization)

\section{Mental and physical health}

robustness

(measure of

resilience)
Regression
Academic
Self-esteem;
Mediation results (attendance and school grades)
Collective self-esteem Depression
Regression




\author{
Mereish Cross-sectional \\ \& Poteat
}

(2015)
Zimmerman, Longitudinal Darnell,
Rhew, Lee,
\& Kaysen

(2015)

Peterson et Longitudinal al. (2014)

Reisner, Cross-sectional Biello, Perry, Gamarel,

\& Mimiaga

(2014)

Herrick et al. Longitudinal (2013)

Walker \&

Longmire-

Avital (2013)

Fredriksen-

Goldsen et

al. (2012)

Cross-sectional

Cross-sectional
Victimization; Internalized stigma; Concealment of sexual orientation; Social support; Size

of social network; Health outcomes (routine examination, financial barriers to health care, obesity, smoking, over drinking, physical activities).

Kurtz,

Buttram,

Surratt, \&

Stall (2012)

Mustanski, Newcomb,

\& Garofalo

(2011)

Poteat, Cross-sectional Mereish,

DiGiovanni, \& Koenig

(2011)

\section{Religious faith; Mental Health (Depression and Anxiety)}

Cross-sectional

Cross-sectional

Sociodemographic Data Victimization; Perceived social support; Peer and family support Depression); Cognitive escape (use of alcohol and / or drugs along with sex); Victimization

General victimization; Homophobic victimization; Parental support Socio-demographic data
Opening of sexual orientation

to friends; Growth relationship with close friend

LGB identity; Externalization of sexual orientation

\section{Homophobia; Racism; Life experience Sociodemographic Data}

Risk: Alcohol use; Bullying; Depression;Protection: Family support; School support; Community Engagement; Sports team; LGBTQ identity; Sociodemographic variables

Intimate partner violence; Internalized homophobia; Socio-demographic data
Psychological suffering

(Depression and anxiety)

Collective

self-esteem;

LGBTQ

Community

Connection

Resilience

HIV infection

Self-harm and suicide attempt

Depression;

Substance use;

Compulsive

sexual behavior

Resilience

Depression; Disability /

Handicap;

Poor general health.

Resilience (coping

behaviors, self-efficacy and social engagement)

Psychological suffering

$\begin{array}{ccc}\begin{array}{c}\text { Educational } \\ \text { concerns } \\ \text { (average }\end{array} & \begin{array}{c}\text { Mediator } \\ \text { variables } \\ \text { (suicide, school }\end{array} & \begin{array}{c}\text { Mediation } \\ \text { and }\end{array} \\ \text { grades, } & \text { affiliation) } & \\ \text { absence } & \text { Moderationg } \\ \text { from school, } & \text { variable } \\ \text { importance } & \text { (parental } \\ \text { of graduation) } & \text { support; } \\ & \text { victimization) }\end{array}$

Internalized homophobia

Internalized Moderation homophobia

Family

Moderation rejection

Correlation and regression

Regression

Correlation

Moderation

Regression

Regression

Regression victimization) 


\begin{tabular}{|c|c|c|c|c|c|}
\hline $\begin{array}{c}\text { Gwadz et al. } \\
(2006)\end{array}$ & Cross-sectional & $\begin{array}{l}\text { Victimization in childhood; } \\
\text { Life events } \\
\text { Sociodemographic } \\
\text { characteristics }\end{array}$ & $\begin{array}{c}\text { Formal } \\
\text { economy; } \\
\text { Home; School } \\
\text { education } \\
\text { (high school); } \\
\text { Absence of } \\
\text { involvement } \\
\text { in the prison } \\
\text { system; Positive } \\
\text { mental health } \\
\text { (depression); } \\
\text { Social support; } \\
\text { non-use of } \\
\text { drugs. }\end{array}$ & -------- & $\begin{array}{c}\text { Correlation } \\
\text { and } \\
\text { regression }\end{array}$ \\
\hline $\begin{array}{l}\text { Russell \& } \\
\text { Richards } \\
(2003)\end{array}$ & Cross-sectional & $\begin{array}{l}\text { Stressors associated with anti- } \\
\text { gay campaigns (homophobia, } \\
\text { internalized homophobia, } \\
\text { community division, sense of } \\
\text { danger); Resilience associated } \\
\text { with anti-gay campaigns (coping } \\
\text { with homophobia, expression of } \\
\text { affection, testimonies of success, } \\
\text { LGB community) }\end{array}$ & -------------- & --------- & Correlation \\
\hline
\end{tabular}

tors continue to be cautiously incorporated into investigations. Examples that were found were: Dyadic adjustment (Bonanno, Moskowitz, Papa, \& Folkman, 2005), family support / acceptance (Reisner et al., 2014), and perception of social support (eg, Mustanski et al., 2011).

Regarding the variables to evaluate positive adaptation (see Table 1), studies used both indicators of internal adaptation (eg, mental / psychological health, subjective well-being) and external indicators related to the accomplishment of developmental tasks expected socially and relational skills (eg, community connection, school / academic success, social conduct, risky sexual behavior, academic and economic qualities). The presence of mental health (e.g., depression, anxiety), however, was highlighted as the most frequently used indicator to assess the positive adaptation of this population.

It is also worth noting that some studies analyzed in this review, even though they conceptually recognize resilience as a process, have assumed that it can be measured directly in a single dimension and explained as the adaptive outcome itself (eg, Buttram et al., 2014; Kurtz et al., 2012; Walker \& Longmire-Avital,
2013), or even as a salient "buffer" effect that can minimize the effects of risks and lead to better health (Figueroa \& Zocolla, 2015; Peterson et al., 2014). For example, two of these studies used the Resilience Scale developed by Wagnild and Young (1993) to assess the level of positive psychosocial adaptation in significant life events (Peterson et al., 2014; Walker \& Longmire-Avital, 2013).

Based on what was described, it can be seen that in these studies which directly measured resilience, it was represented as a result / outcome. Thus, it is not the positive adaptation, through health indicators, well-being or even fulfillment of developmental tasks, that suggest resilience, but that which indicates positive adjustment, from your personal capabilities. It is assumed, however, that resilience is a process that leads to positive adaptation. It is not the ideal end point that individuals need to reach, and therefore, is not kept in a permanent state, rather it is a continuous process that involves the interactional processes between individuals and their environment and that can be developed over time, with positive adaptation being its outcome (Hill \& Gunderson, 2015). 
Despite notable advances in resilience studies with a focus on variables and sexual minorities, incorporating a more positive perspective and highlighting the potentialities of this population, many studies continue to operationalize it by methodologically considering only variables with individual attributes as promoters of psychosocial development. In addition, adaptation itself has also been assessed on the basis of more individual criteria related to mental health. It should be stressed, however, that the notion of resilience associated with individual characteristics can minimize the importance of the social environment and hold individuals accountable only for their (lack of) success, disregarding the role of social, political, economic and cultural forces that can promote or even inhibit the processes of resilience. Of course, among many other factors, the inclusion of efficient public policies is a facilitator of resilience, especially among socially marginalized groups (Ungar, 2015).

\section{Data Analysis Models}

Three main operational models were identified to analyze the processes of resilience: (a) compensatory model or principle effect $(n=12)$, (b) mediator model $(n=3)$, and (c) moderator model $(n=4)$. From the empirical studies investigated, 12 adopted the compensatory or principle effects model to explain resilience, especially from the analysis of the direct effect of the independent variables (risk and / or protection) on the dependent variables (positive adjustment / adjustment). To arrive at these - non causal - explanations simple correlation and regression methods were the main analytical strategies used (See Table 1). Using the correlation model, for example, Reisner et al. (2014) observed that self-harming behavior was positively associated with suicide in LGBTQ (lesbian, gay, bisexual, transgender and queer) and heterosexual adults. In turn, regression analysis showed that family support was associated with a higher likelihood of selfharming behaviors and suicidal tendencies. Thus, a protective factor (family support) acted against the risk factor (self-harm), compensating for the negative effects on the results of psychosocial adjustment (suicide).

Studies that adopted the mediation model ( $n$ $=3$ ), reflected the sequence in which independent variables (risk factors and protection factors) cause indirect effects on one or more mediating variables, and this effect is propagated to the variables of outcome (positive adaptation). For example, the disclosure of LGBT identity of young students to schoolmates and teachers was related to high rates of victimization but also associated with high self-esteem, which contributed to a lower rate of depression (Kosciw et al., 2015). Thus, the mediating variables (victimization and self-esteem) were influenced by the independent variable (disclosure of sexual orientation) and indirectly had an effect on adaptation (depression). In another mediation study it was found that internalized homophobia partially mediated the effect of experiences of stigma related to sexual orientation in relation to depression symptoms (Bruce et al., 2015). In addition, the results suggest that LGBT people who experienced stigma and as a result, experienced stress by hiding sexual orientation, eventually sought social support from other LGBT people, which contributed to the development of positive identity. These results support the idea that the indirect effects of homophobic victimization on LGB individuals are mediated by internalized homophobia, further damaging the psychological health of the LGB population.

On the other hand, moderation studies $(n=4)$ showed how a moderating variable affects the direction and/or strength of the relationship between independent variables (risk and protection) and the dependent variable/ outcome (positive adaptation). In a longitudinal regression study with 843 young adult lesbian and bisexual women, it was observed that when they revealed their sexual orientation to their family, even with a high rate of family rejection (moderating variable), they showed resilience by finding connections with the community of sexual minorities and experienced collective 
self-esteem (Zimmerman et al., 2015). However, when stigma becomes a concern, motivations increase to hide LGBT orientation, as well as an increase in other risk factors of sexual identity, showing less connection to the community. Another example can be seen in the study by Mereish and Poteat (2015) in which young LGBT people who established close relationships with close friends (LGBT or heterosexual) were associated with less psychological suffering for sexual minorities with a low level of internalized homophobia (moderate variable). For participants with high levels of homophobia, growth relationships with an LGBT friend were associated with less psychic suffering, but this was not the case with a heterosexual friend.

Although previous identification of the association of risk and protective variables as predictors of the adaptive outcomes of the LGB population is important, it must be recognized that the impact of these factors may be different between LGB individuals, their families and communities. In regard to risks, for example, although they represent a threat to the quality of adaptation in resilience processes, it is emphasized that risk is a probabilistic term, being that in its presence, there is the probability of a negative result for members of a particular group, but this does not necessarily indicate the exact nature of the threat to an individual (Wright \& Masten, 2015). Risks are multifaceted aspects and a more rigorous assessment of their effects needs to consider their cumulative effect, chronicity, the ecological complexity in which the person is involved when facing the threatening situation, as well as the relevance of the cultural and contextual factors that affect people (Ungar, 2015; Wright \& Masten, 2015).

In addition, it is important to note that, based on the results analyzed in this review, the same variable can function as a risk / vulnerability in one given context, but in another context could be seen as a protection factor. For example, disclosure of LGBT identity may be related to high victimization rates, but can also be associated with elevated self-esteem (eg, Kosciw et al., 2015). The revelation of sexual orientation may be a risk factor by placing sexual minorities in the face of homophobic prejudice. On the other hand, this process of identity affirmation can increase self-esteem and enable better adaptive results.

The methodological investigation of resilience therefore requires a complex assessment of risks, protective aspects and positive adaptation. The inconsistency in the operationalization of these factors may undermine the understanding and generalization of the empirical results (Masten, 2015). Mediation and moderation studies reveal subtlety and complexity in assessing the set of systems and processes that collaborate or not in the resilience processes in sexual minorities. Their results indicate that it is not possible to establish a relationship of linear causality and apparent determinism between risk factors and protection of biopsychosocial adjustment among LGB individuals, but involves the understanding of multiple pathways and contexts of risk and being able to overcome.

\section{Studies Focused on the Person}

Herein, resilience can be operationalized through the meanings that the LGBT population attributes to the challenges they face in their life trajectories, as well as the strategies they use to overcome challenging events (eg, Sung, Szymanski, \& Henrichs-Beck, 2015). The goal, therefore, is not to generalize results, but to identify the variety of contexts of adversity experienced, as well as the coping and stories of overcoming of real people, which point to the complexity of the resilience processes involving with LGB people. Table 2 presents a description of the instruments used in each study, the data analysis methods and the main thematic categories.

Among the articles selected in this review, eight were person-centered, all were qualitative, with a cross - sectional design and published between the years 2003 and 2015. 
Table 2

Characterization of Qualitative (person-focused) Studies of Resilience and the LGB Population by Year of Publication

\begin{tabular}{|c|c|c|c|c|}
\hline Studies & Study Design & Instruments & Category themes & $\begin{array}{c}\text { Data analysis } \\
\text { models }\end{array}$ \\
\hline $\begin{array}{l}\text { Farr, Crain, } \\
\text { Oakley, } \\
\text { Cashen, \& } \\
\text { Garber (2016) }\end{array}$ & Cross-sectional & $\begin{array}{l}\text { Semi-structured } \\
\text { interviews and } \\
\text { videotape } \\
\text { sessions }\end{array}$ & $\begin{array}{c}\text { Categories of analysis: (a) Feelings of } \\
\text { difference, (b) Microaggressions, and (c) } \\
\text { Resilience (positive conceptions about } \\
\text { family) }\end{array}$ & $\begin{array}{l}\text { Thematic } \\
\text { analysis }\end{array}$ \\
\hline $\begin{array}{c}\text { Erhard \& } \\
\text { Ben-Ami, } \\
(2015)\end{array}$ & Cross-sectional & $\begin{array}{l}\text { Semi-structured } \\
\text { interviews }\end{array}$ & $\begin{array}{l}\text { Ecological protection factors (minority } \\
\text { coping group, virtual LGB defense } \\
\text { community, and acceptance of } \\
\text { heterosexual peers in school); Facing } \\
\text { mechanisms (cognitive assessment of } \\
\text { anti-LGB incidents at school, assertive } \\
\text { communication, becoming a lawyer on } \\
\text { behalf of the LGB community, tactically } \\
\text { ignoring, questioning and resisting } \\
\text { sexual labels) }\end{array}$ & $\begin{array}{l}\text { Theory } \\
\text { based }\end{array}$ \\
\hline $\begin{array}{c}\text { Foster, } \\
\text { Bowland, \& } \\
\text { Vosler (2015) }\end{array}$ & Cross-sectional & Open interview & $\begin{array}{l}\text { Transforming theological meanings; } \\
\text { Discovery of a safe community; } \\
\text { Remain in community; Seeking a new } \\
\text { community; Working for social justice }\end{array}$ & Theory based \\
\hline $\begin{array}{l}\text { Gray, } \\
\text { Mendelsonhn, } \\
\text { \& Omoto } \\
\text { (2015) }\end{array}$ & Cross-sectional & $\begin{array}{l}\text { Semi-structured } \\
\text { interviews }\end{array}$ & $\begin{array}{l}\text { (Dis)connection with the LGBT } \\
\text { community; (Dis)connection with the } \\
\text { Latino community; Challenges and } \\
\text { intersectional strategies; Welfare, } \\
\text { strength and resilience }\end{array}$ & $\begin{array}{l}\text { Content } \\
\text { analysis }\end{array}$ \\
\hline $\begin{array}{l}\text { Sung et al. } \\
\text { (2015) }\end{array}$ & Cross-sectional & Open interview & $\begin{array}{l}\text { Challenges (Living with multiple } \\
\text { minority identities; Invisibility; Sexual } \\
\text { stereotypes, Fantasies and Fetishism; } \\
\text { Facing oppression based on sexual } \\
\text { orientation); Coping Strategies (Identity } \\
\text { Management Strategy; Empowerment } \\
\text { Strategies); Positive aspects (sources } \\
\text { of sociocultural strength; Insight and } \\
\text { empathy with oneself and with others) }\end{array}$ & $\begin{array}{l}\text { Content } \\
\text { analysis }\end{array}$ \\
\hline $\begin{array}{c}\text { Harper, } \\
\text { Bruce, Hosek, } \\
\text { Fernandez, \& } \\
\text { Rood (2014) }\end{array}$ & Cross-sectional & $\begin{array}{l}\text { Semi-structured } \\
\text { interviews }\end{array}$ & $\begin{array}{l}\text { Engagement in processes that promote } \\
\text { cognitive health; Maintain healthy } \\
\text { behavioral practices; (Receive social } \\
\text { support from others; Empower other } \\
\text { young gay / bisexual men }\end{array}$ & $\begin{array}{c}\text { Phenomenological } \\
\text { Analysis }\end{array}$ \\
\hline $\begin{array}{l}\text { DiFulvio } \\
\text { (2011) }\end{array}$ & Cross-sectional & $\begin{array}{l}\text { Interviews and } \\
\text { focus groups }\end{array}$ & $\begin{array}{l}\text { Social connection to an individual (self } \\
\text { affirmation); Social connection to a group } \\
\text { (meeting other people like yourself); } \\
\text { Social connection to a group (work for } \\
\text { change) }\end{array}$ & $\begin{array}{l}\text { Content } \\
\text { analysis }\end{array}$ \\
\hline $\begin{array}{l}\text { Bowleg, } \\
\text { Huang, Brooks, } \\
\text { Black, \& } \\
\text { Burkholder } \\
\text { (2003) }\end{array}$ & Cross-sectional & $\begin{array}{l}\text { Semi-structured } \\
\text { interviews }\end{array}$ & $\begin{array}{l}\text { Multiple minority stress (racism, } \\
\text { sexism, heterosexism); Resilience } \\
\text { (external environmental context, human- } \\
\text { environment interaction processes, } \\
\text { internal characteristics, resilience } \\
\text { processes, positive life outcome, socially } \\
\text { supportive relationships) }\end{array}$ & $\begin{array}{l}\text { Theory } \\
\text { based }\end{array}$ \\
\hline
\end{tabular}




\section{Instruments for Data Collection}

In relation to the instruments used in the qualitative studies, were mainly identified the use of the semistructured or open interview. In this way, the LGB person's life history was privileged, providing information about the significant challenges they experienced during their life trajectory, but above all, they pointed to the resources and protection systems that had been accessed over time and which reflected the resilience processes. Examples of questions that the authors used to ask about these processes were: "What were the processes and key factors in integrating your identity with being both gay / lesbian and Christian?" (Foster et al., 2015); as well as "Please tell me about the challenges you experience in everyday life as a lesbian / bisexual Asian American"; and "Please tell me about the ways you deal with and / or withstand the day-to-day challenges you face as a lesbian / bisexual Asian American?" (Sung et al., 2015). Thus, more than an interview, the researchers proposed that the participants report their life histories, in order to capture in greater detail the reality of sexual minorities.

\section{Methods of Data Analysis and Thematic Categories}

The main methods of analysis in the personcentered studies in this review refer mainly to content analysis $(n=4)$, grounded-theory $(n=$ $3)$ and phenomenological analysis $(n=1)$. These methodological strategies emphasized the richness of the meanings attributed to life experience, when considering the dynamic, procedural and provisional character of resilience (Yunes, 2003). Thus, in an inductive way, the categories of analysis emerged from the narrated life histories of the participants rather than from a previous theory. Table 2 presents the thematic categories of each study.

In regard to the thematic categories, it was observed that they were mainly related to the description of the challenges faced, as well as the protective resources that are needed for the adaptive processes of sexual minorities. Similar- ly to the studies which focused on the variable, the main risk factor reported by the participants was related to the experiences of homophobic discrimination, be it from the family, school, institutional or cultural (e.g., DiFulvio, 2011; Erhard \& Ben-Ami, 2015). Participants described, for instance, having suffered from homophobic bullying, being targets of violence for having an unusual appearance and acting different from the socially established norm or even being accompanied by an LGBT person, which leads to a disconnection of these people from their communities (e.g., DiFulvio, 2011). In addition, the management of multiple minority identities (LGB, immigrant, black) reveals daily tensions and sources of stress in their lives, especially as a result of heterosexism, racism and sexism (e.g., Bowleg et al., 2003). See other thematic categories in Table 2.

The studies analyzed here also explored the various strategies that LGB people used to face and overcome the challenges and stresses that accompanied their lives and placed them in a situation of risk, for example: managing minority identities and seeking empowerment (Sung et al., 2015), finding connection with the LGBT community and the racial / ethnic community (Gray et al., 2015), having socially supportive relationships, feelings of uniqueness, self-esteem, social behaviors and skills, happiness, optimism and humor (Bowleg et al., 2003), engaging in processes that promote cognitive health, maintaining healthy behavioral practices, empowering other young gay / bisexual men (Harper et al., 2014), and individual and group affiliation serving to affirm identity and provide a forum in which personal struggle becomes collective action (DiFulvio, 2011).

The thematic categories of qualitative studies also revealed the adaptability of LGB individuals, showing health and well-being, even after dealing with the negative experiences that accompany their lives. For example, in a study of 13 gay Latino immigrants, the sources of stress and challenges as well as opportunities related to the resilience of this minority group were explored qualitatively (Gray et al., 2015). In their 
reports they stated that the challenges they experienced were a source of growth and personal development, providing a sense of strength and achievement. This was mainly because they sought sources of social and community support, cultivated social relations, sought psychotherapeutic resources, and worked for self-acceptance and pride in themselves.

Based on the data of this review, it is evident that studies focused on the person endeavored to understand the complexity that involves the dimensions of coping and overcoming the experiences of pain and suffering experienced by LGB families. One highlight of these investigations was the emphasis on protection factors, incorporating a salutogenic perspective in the dynamic development of resilience among LGB individuals, making flexible the pathological notions associated with homosexuality and illuminating their healthy aspects and success stories, be it individually, in family, or culturally. In addition, the understanding of how these people overcome the adversities can collaborate in the discovery of preventive and interventionist actions, in order to reinforce the systems of protection and to reduce risks present in the daily life of sexual minorities.

It should be noted that the qualitative studies of this review highlight the specific cultural and contextual aspects of resilience in LGB individuals, with attention given to the influence of culture on risk factors (e.g., multiple contexts of minorities - sexual, racial, ethnic) and protective resources (e.g., rescue of cultural identity).

Person-centered studies have thus facilitated the exploration of rich contextual data in the lives of sexual minorities, providing a holistic and in-depth picture of the lives of LGB individuals who have lived, or still live in adversity. Moreover, the variable-centered studies are a photograph of resilience, taken at a given moment in LGB people's lives, informing the relationship between risk, protection and positive adaptation variables, qualitative studies have a set of photographs or a film told by the participant himself, reporting singularly and in depth the plurality of everyday events present in their individual, family and cultural actions.

\section{Studies Focused on the Person and the Variable}

Four studies from this review integrated the person-centered and variable models to methodologically assess resilience (See Table 3). Two of these studies sought, quantitatively, to find common and differential aspects between the prediction variables (risk and protection) and the outcome variables (adaptation), and qualitatively, to thoroughly understand the resilience processes reported from the meaning that the participants attribute to their life experiences (Kubicek et al., 2013; Rodríguez \& Calle, 2013).

Rodríguez and Calle (2013), for instance, conducted a descriptive and cross-sectional study to explore aspects related to mental health and resilience in 44 gay, lesbian and bisexual youths. In this quantitative research, they used a self applied questionnaire and explored issues such as: aspects of gay identity, indicators of internalized oppression, discrimination, the family's knowledge about sexual orientation, mental health and behavior associated with suicide. In addition, they applied a scale to measure resilience developed by Lever and Valdez (2010), consisting of five dimensions: strength and confidence, social competence, family support, support and social structure. With the justification of extending the reflection and exploring the meaning attributed to the experiences raised in the quantitative study, the authors conducted semi-structured interviews. The results support the idea that the experience of having a sexual orientation different from the heteronormative presents specific challenges for these young people.

Finally, two other studies sought to verify similarities and differences in the different trajectories, identifying adaptation profiles in the context of risk- grief and homophobic victimization, respectively (Bonanno et al., 2005; Livingston et al., 2015), and subsequently from the identification of adaptive groups, they established relationships between predictor and outcome variables. For example, Livingston et al. (2015), with a cluster analysis, empirically traced distinct personality profiles among LGB young adults: adaptive (lower neuroticism and 


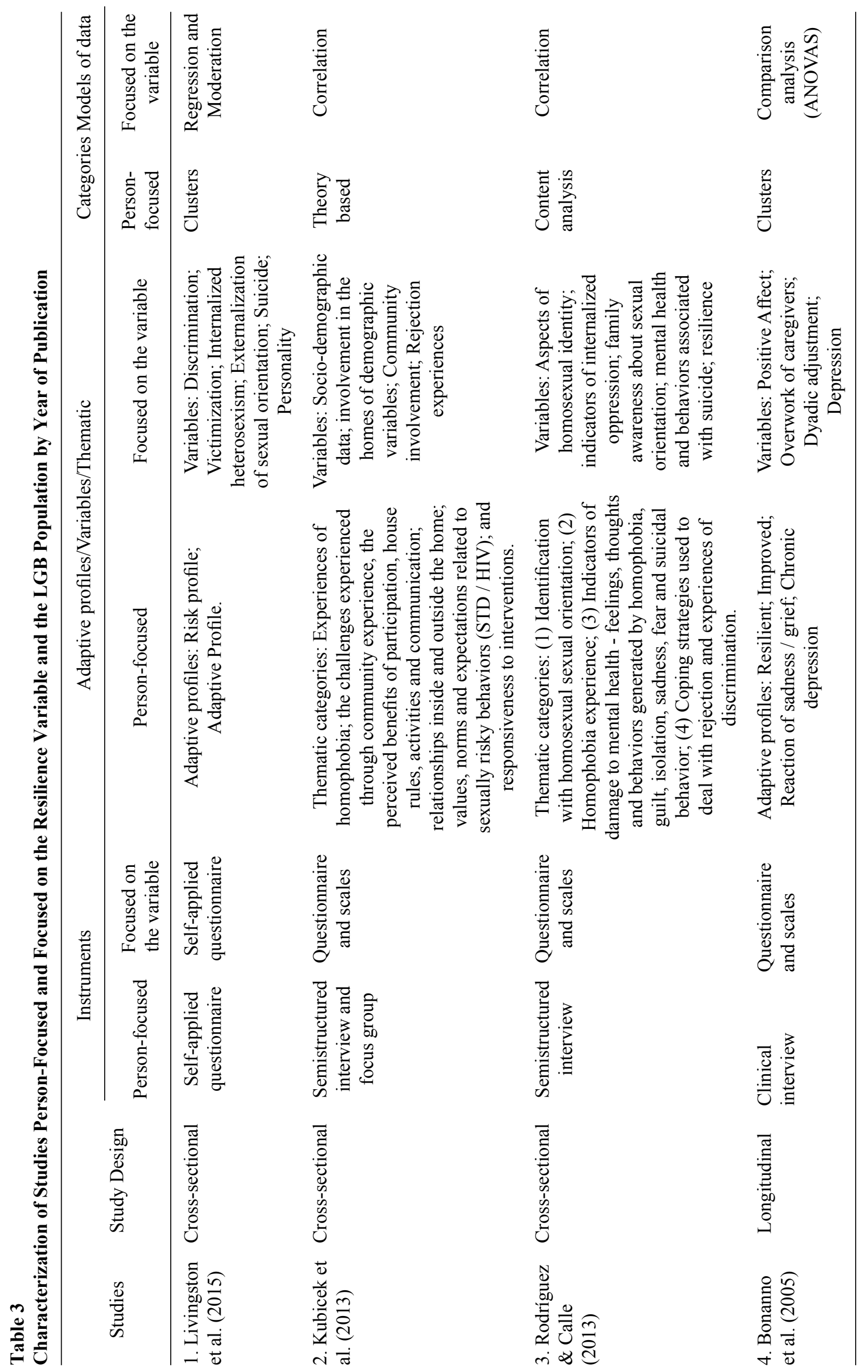


greater extroversion, kindness, awareness, and sincerity); and at risk (higher neuroticism and lower kindness, conscientiousness, openness and extroversion). Subsequently, logistic regressions suggested that the group with an adaptive personality had a lower risk of attempting suicide in the face of victimization than the risk group.

It was observed, therefore, that the number of studies that combine the models focused on the variable and on the person is still limited. For Masten (2015), the combination of these two analytical processes is a significant advance for resilience studies, as it would explain and delineate multiple paths between individuals over time, and increase the ability to evaluate the various resources that reflect resilient processes. Quantitatively, we can strengthen statistical data and look for specific and differential aspects between predictors and outcomes, as well as suggest universal standards in the negotiation to achieve developmental outcomes that are culturally relevant. Qualitatively, the analyzes can capture the outstanding patterns in the lives of people and their communities and find greater heterogeneity in the processes of resilience, by extracting from their own life histories the strategies of coping and overcoming adversities experienced over time.

\section{Final Considerations}

This study aimed to analyze the methodological strategies for resilience research in empirical studies with LGB individuals, based on an integrative review of the literature. From the selected studies research was found with a focus on the variable, as well as studies focusing on the person and, to a lesser extent, mixed studies, centered on the person and the variable simultaneously.

In general, the results of this integrative review of the literature reveal the complexity and multiplicity of methodological paths present in resilience studies with sexual minorities. The measurement and / or understanding of resilience is not a simplistic task, but it involves observation and dialogue between risk factors, protection and positive adaptation, as well as dialectically involving the different levels and contexts involved: individual, family, community and cultural.

Despite the methodological advances in investigating resilience using studies with the LGB population, when analyzing the complexity involved in this process and also highlighting the potentialities of sexual minorities, some limits in the reviewed studies were noticed and deserve to be mentioned, in order to suggest possibilities for future investigations. First, it is important to consider that advances in resilience research depend to some extent on the existence of a more consensual definition of resilience. That is, as observed throughout this review, there are still some divergences in the concept of resilience, which is sometimes defined as a process, a result of the interaction between risk and protection and obtaining positive adaptation as the result of this interaction. However, resilience is also sometimes explained as the adaptation result itself (e.g., Buttram et al., 2014), or as a salient "buffer" that can cushion the effects of risks and lead to a better state of health for LGB people (Peterson et al., 2014; Rodríguez \& Calle, 2013). Thus, these conceptual variations hinder the investigation of resilience and may compromise its operationalization, as well as question its applicability in the intervention and promotion of good health in sexual minorities (Colpitts \& Gahagan, 2016).

The methodological challenges, in part, are also found through the quality of the information that is collected. In this way, the use of instruments as well as the adequacy of their applicability are pertinent in capturing in depth the nuances of the LGB person's resilience processes. From the analyzed data it was noticed that the researches with a focus on the variables continued to use variables and measurement instruments with an emphasis on the individual aspects to capture the resilience. However, it is not a condition of solitary individuals (Ungar, 2015). Analytical models therefore need to recognize the complex and multidimensional nature that accompanies the lives of sexual minorities and thereby show the resources that surround their ecological context (family, community, cultural, 
political, and legal) in relation to their personal experiences. By focusing on the individual rather than the social dimension, research continues to contribute to the invisibility of the needs of sexual minorities (Meyer, 2015).

More advanced statistical analyzes are also needed in order to grasp the more complex aspects that are involved in the lives of LGB people. For example, the use of multilevel modeling (MLM) in variable-focused surveys to investigate the interdependence of data between family, marital and parental peers is recommended; analysis of clusters in person-centered studies to delineate the profiles or trajectories of sexual minority adjustment; as well as advancement in mediation and moderation studies. It could be determined from the person-centered, mainly qualitative studies, that the interview (open, semi-structured and structured) was the main instrument for data collection. However, it is suggested that a number of methods of data collection should be cross-referenced in order to creatively and more deeply capture the LGB person's life experience. For example, the use of narratives, photographs, field diaries, ecological insertion, and films are examples of instruments that may allow more consistent qualitative indicators to be reached. Cross-referencing is important to gain insight into the multidimensional experience of sexual minorities. Another limitation is that most of the studies used a cross-sectional design in their investigations. Therefore, it is necessary to exercise caution when assigning causal directions to the associations between risk, protection and adaptation factors that were found. Longitudinal studies of resilience are increasingly indicated in research with LGB individuals, in order to point out if, for example, protection resources contribute to their biopsychosocial development over time.

Some limits were also imposed on this review. First, so as to establish a more rigorous inclusion / exclusion criteria for the research, the following were left out: systematic reviews and narratives, technical articles, theses and dissertations, as well as book chapters that could offer a more comprehensive and integrated view of the state of the art on the subject of resilience and the LGB population. In addition, other databases such as Scopus andWeb of Science, for example, could also have been included, broadening the understanding of the state of the art of the subject studied here. At the same time, the broadening of the search can contribute to the consolidation of the resilience construct in the promotion of practical strategies aimed at improving the health and well-being of sexual minorities.

Gays and lesbians continue to maintain their relationships in a context marked by homophobic discrimination and unprotected public policy (Doyle \& Molix, 2015; Lira \& Morais, 2017). Certainly, by identifying resilience at the various ecological levels where sexual minorities are present, the chances of delineating interventions in a variety of contexts (the family, health facilities, education, social care) are increased in order to to minimize risks or exposure to the adversities that accompany the lives of sexual minorities, to increase the propensities of their development, and to strengthen or restore their adaptive systems (Wright \& Masten, 2015).

\section{References}

Azevedo, R. S. (2010). Sobrecarga do cuidador informal da pessoa idosa frágil: Uma revisão sistemática (Unpublished master thesis, Universidade Federal de Minas Gerais, Belo Horizonte, MG, Brazil).

*Bonanno, G. A., Moskowitz, J. T., Papa, A., \& Folkman, S. (2005). Resilience to loss in bereaved spouses, bereaved parents, and bereaved gay men. Journal of Personality and Social Psychology, 88(5), 827. doi: 10.1037/00223514.88.5.827

*Bowleg, L., Huang, J., Brooks, K., Black, A., \& Burkholder, G. (2003). Triple jeopardy and beyond: Multiple minority stress and resilience among black lesbians. Journal of Lesbian Studies, 7(4), 87-108. doi: 10.1300/ J155v07n04 06

*Bruce, D., Harper, G. W., \& Bauermeister, J. A. (2015). Minority stress, positive identity development, and depressive symptoms: Implications for resilience among sexual minority male youth. Psychology of Sexual Orientation and Gender Diversity, 2(3), 287. doi: http://dx.doi. org/10.1037/sgd0000128 
*Buttram, M. E., Surratt, H. L., \& Kurtz, S. P. (2014). Risk and protective factors associated with personal mastery among sexual minority AfricanAmerican female sex workers. Journal of Gay \& Lesbian Social Services, 26(4), 407-425. doi: $10.1080 / 10538720.2014 .956242$

Colpitts, E., \& Gahagan, J. (2016). The utility of resilience as a conceptual framework for understanding and measuring LGBTQ health. International Journal for Equity in Health, 15(1), 1. doi: 10.1186/s12939-016-0349-1

*DiFulvio, G. T. (2011). Sexual minority youth, social connection and resilience: From personal struggle to collective identity. Social Science \& Medicine, 72(10), 1611-1617. doi: 10.1016/j. socscimed.2011.02.045

Doyle, D. M., \& Molix, L. (2015). Social stigma and sexual minorities' romantic relationship functioning: A meta-analytic review. Personality and Social Psychology Bulletin, 41(10), 13631381. doi: $10.1177 / 0146167215594592$

*Erhard, R. L., \& Ben-Ami, E. (2015). The schooling experience of lesbian, gay, and bisexual youth in lsrael: Falling below and rising above as a matter of social ecology. Journal of homosexuality, 63(2), 193-227. doi: 10.1080/00918369.2015.1083778

*Farr, R. H., Crain, E. E., Oakley, M. K., Cashen, K. K., \& Garber, K. J. (2016). Microaggressions, feelings of difference, and resilience among adopted children with sexual minority parents. Journal of Youth and Adolescence, 45(1), 85-104. doi: 10.1007/s10964-015-0353-6

*Figueroa, W. S., \& Zoccola, P. M. (2015). Individual differences of risk and resiliency in sexual minority health: The roles of stigma consciousness and psychological hardiness. Psychology of Sexual Orientation and Gender Diversity, 2(3), 329. doi: http://dx.doi.org/10.1037/sgd0000114

*Foster, K. A., Bowland, S. E., \& Vosler, A. N. (2015). All the pain along with all the joy: Spiritual resilience in lesbian and gay Christians. American Journal of Community Psychology, 55(1-2), 191-201. doi: 10.1007/s10464-015-9704-4

*Fredriksen-Goldsen, K. I., Emlet, C. A., Kim, H. J., Muraco, A., Erosheva, E. A., Goldsen, J., \& Hoy-Ellis, C. P. (2012). The physical and mental health of lesbian, gay male, and bisexual (LGB) older adults: The role of key health indicators and risk and protective factors. The Gerontologist, 53(4), 664-675. doi: 10.1093/geront/gns123
*Fredriksen-Goldsen, K. I., Kim, H. J., Shiu, C., Goldsen, J., \& Emlet, C. A. (2015). Successful aging among LGBT older adults: Physical and mental health-related quality of life by age group. The Gerontologist, 55(1), 154-168. doi: 10.1093/geront/gnu081

*Gray, N. N., Mendelsohn, D. M., \& Omoto, A. M. (2015). Community connectedness, challenges, and resilience among gay Latino immigrants. American Journal of Community Psychology, 55(1-2), 202-214. doi: 10.1007/s10464-0149697-4

*Gwadz, M. V., Clatts, M. C., Yi, H., Leonard, N. R., Goldsamt, L., \& Lankenau, S. (2006). Resilience among young men who have sex with men in New York City. Sexuality Research and Social Policy Journal of NSRC, 3(1), 13-21. doi: 10.1525/srsp.2006.3.1.13

*Harper, G. W., Bruce, D., Hosek, S. G., Fernandez, M. I., \& Rood, B. A. (2014). Resilience processes demonstrated by young gay and bisexual men living with hiv: Implications for intervention. AIDS Patient Care and STDs, 28(12), 666676. doi: 10.1525/srsp.2006.3.1.13

*Herrick, A. L., Stall, R., Chmiel, J. S., Guadamuz, T. E., Penniman, T., Shoptaw, S., ...Plankey, M. W. (2013). It gets better: Resolution of internalized homophobia over time and associations with positive health outcomes among MSM. AIDS and Behavior, 17(4), 1423-1430. doi: 10.1007/ s10461-012-0392-x

Hill, C. A., \& Gunderson, C. J. (2015). Resilience of lesbian, gay, and bisexual individuals in relation to social environment, personal characteristics, and emotion regulation strategies. Psychology of Sexual Orientation and Gender Diversity, 2(3), 232. doi: $10.1037 /$ sgd0000129

*Kosciw, J. G., Palmer, N. A., \& Kull, R. M. (2015). Reflecting resiliency: Openness about sexual orientation and/or gender identity and its relationship to well-being and educational outcomes for LGBT students. American Journal of Community Psychology, 55(1-2), 167-178. doi: 10.1007/s10464-014-9642-6

*Kubicek, K., McNeeley, M., Holloway, I. W., Weiss, G., \& Kipke, M. D. (2013). "It's like our own little world": Resilience as a factor in participating in the ballroom community subculture. AIDS and Behavior, 17(4), 1524-1539. doi: 10.1007/s10461-012-0205-2 
*Kurtz, S. P., Buttram, M. E., Surratt, H. L., \& Stall, R. D. (2012). Resilience, syndemic factors, and serosorting behaviors among HIVpositive and HIV-negative substance-using MSM. AIDS Education and Prevention: Official Publication of the International Society for AIDS Education, 24(3), 193. doi: 10.1521/ aeap.2012.24.3.193

Kwon, P. (2013). Resilience in lesbian, gay, and bisexual individuals. Personality and Social Psychology Review, 17(4), 371-383. doi: $10.1177 / 1088868313490248$

Lever, J. P., \& Valdez, N. E. G. (2010). Desarrollo de una escala de medicion de la residencia con mexicanos (RESI-M). Interdisciplinaria, 27(1), 7-23. Retrieved from http://www.redalyc.org/ pdf/180/18014748002.pdf

Liberati, A., Altman, D. G., Tetzlaff, J., Mulrow, C., Gotzsche, P. C., Ioannidis, J. P. A., ...Moher, D. (2009). The PRISMA statement for reporting systematic reviews and meta-analyses of studies that evaluate health care interventions: Explanation and elaboration. Annals of Internal Medicine, 151(4), 65-94. doi: https://doi.org/10.1136/ bmj.b2700

Lira, A. N., \& Morais, N. A. (2017). Resilience in lesbian, gay and bisexual (LGB) populations: An integrative literature review. Sexuality Research and Social Policy. doi: 10.1007/s13178-0170285-x

*Livingston, N. A., Heck, N. C., Flentje, A., Gleason, H., Oost, K. M., \& Cochran, B. N. (2015). Sexual minority stress and suicide risk: Identifying resilience through personality profile analysis. Psychology of Sexual Orientation and Gender Diversity, 2(3), 321. doi: http://dx.doi. org/10.1037/sgd0000116

Luthar, S. S., Cicchetti, D., \& Becker, B. (2000). The construct of resilience: A critical evaluation and guidelines for future work. Child Development, 71, 543-62. Retrieved from http://www.ncbi. nlm.nih.gov/pubmed/10953923

Lyons, A. (2015). Resilience in lesbians and gay men: A review and key findings from a nationwide Australian survey. Internacional Review of Psychiatry, 29, 1-9. doi: 10.3109/09540261.2015.1051517

*Mason, T. B., Lewis, R. J., Winstead, B. A., \& Derlega, V. J. (2015). External and internalized heterosexism among sexual minority women: The moderating roles of social constraints and collective self-esteem. Psychology of Sexual Orientation and Gender Diversity, 2(3), 313-320. doi: http://dx.doi.org/10.1037/sgd0000115

Masten, A. S. (2015). Ordinary magic. Resilience in development. New York: Guilford Press.

Masten, A. S., \& Monn, A. R. (2015). Child and family resilience: A call for integrated science, practice and professional training. Family Relations, 64, 5-21. doi: 10.1111/fare.12103

*Mereish, E., \& Poteat, V. P. (2015). Effects of heterosexuals' direct and extended friendships with sexual minorities on their attitudes and behaviors: Intergroup anxiety and attitude strength as mediators and moderators. Journal of Applied Social Psychology, 45(3), 147-157. doi: http:// dx.doi.org/10.1037/sgd0000121

Meyer, I. H. (2015). Resilience in the study of minority stress and health of sexual and gender minorities. Psychology of Sexual Orientation and Gender Diversity, 2(3), 213-219. doi: http:// dx.doi.org/10.1037/sgd0000132

*Mustanski, B., Newcomb, M. E., \& Garofalo, R. (2011). Mental health of lesbian, gay, and bisexual youths: A developmental resiliency perspective. Journal of Gay \& Lesbian Social Services, 23(2), 204-225. doi: 10.1080/10538720.2 011.561474

*Peterson, J. L., Bakeman, R., Sullivan, P., Millett, G., Rosenberg, E., Salazar, L., ...Frew, P. (2014). Social discrimination and resiliency are not associated with differences in prevalent HIV infection in black and white men who have sex with men. Journal of Acquired Immune Deficiency Syndromes, 66(5), 538. doi: 10.1097/ QAI.0000000000000203

*Poteat, V. P., Mereish, E. H., DiGiovanni, C. D., \& Koenig, B. W. (2011). The effects of general and homophobic victimization on adolescents' psychosocial and educational concerns: The importance of intersecting identities and parent support. Journal of Counseling Psychology, 58(4), 597. doi: $10.1037 / \mathrm{a} 0025095$

*Reisner, S. L., Biello, K., Perry, N. S., Gamarel, K. E., \& Mimiaga, M. J. (2014). A compensatory model of risk and resilience applied to adolescent sexual orientation disparities in nonsuicidal self-injury and suicide attempts. American Journal of Orthopsychiatry, 84(5), 545. doi: 10.1037/ ort0000008 
*Rodríguez, M. D. C. F., \& Calle, F. V. (2013). En torno al rechazo, la salud mental y la resiliencia en un grupo de jóvenes universitarios gays, lesbianas y bisexuales. Revista Griot, 6(1), 44. Retrieved from http://www.ncbi.nlm.nih.gov/pmc/ articles/PMC4318519/

*Russell, G. M., \& Richards, J. A. (2003). Stressor and resilience factors for lesbians, gay men, and bisexuals confronting antigay politics. American Journal of Community Psychology, 31(3-4), 313-328. doi: 10.1023/A:1023919022811

*Shilo, G., Antebi, N., \& Mor, Z. (2015). Individual and community resilience factors among lesbian, gay, bisexual, queer and questioning youth and adults in israel. American Journal of Community Psychology, 55(1-2), 215-227. doi: 10.1007/ s10464-014-9693-8

*Sung, M. R., Szymanski, D. M., \& Henrichs-Beck, C. (2015). Challenges, coping, and benefits of being an Asian American lesbian or bisexual woman. Psychology of Sexual Orientation and Gender Diversity, 2(1), 52. doi: http://dx.doi. org/10.1037/sgd0000085

Ungar, M. (2015). Resilience and culture: The diversity of protective processes and positive adaptation. In L. C. Theron, L. Liebenberg, \& M. Ungar, Youth resilience and culture (pp. 37-48). Dordrecht, Netherlands: Springer. doi: 10.1007/978-94-017-9415-2_3.
Wagnild, G., \& Young, H. (1993). Development and psychometric. Journal of Nursing Measurement, 1(2), 165-178.

*Walker, J. N. J., \& Longmire-Avital, B. (2013). The impact of religious faith and internalized homonegativity on resiliency for black lesbian, gay, and bisexual emerging adults. Developmental Psychology, 49(9), 1723. doi: 10.1037/a0031059

Wright, M. O. D., \& Masten, A. S. (2015). Pathways to resilience in context. In L. C. Theron, L. Liebenberg, \& M. Ungar, Youth resilience and culture (pp. 3-22). Dordrecht, Netherlands: Springer.

Yunes, M. A. M. (2003). Psicologia positiva e resiliência: O foco no indivíduo e na família. Psicologia em Estudo, 8(1), 80-95.

*Zimmerman, L., Darnell, D. A., Rhew, I. C., Lee, C. M., \& Kaysen, D. (2015). Resilience in community: A social ecological development model for young adult sexual minority women. American Journal of Community Psychology, 55(1-2), 179-190. doi: 10.1007/s10464-015-9702-6

Received: 03/04/2017

$1^{\text {st }}$ revision: $29 / 05 / 2017$

$2^{\text {nd }}$ revision: $13 / 08 / 2017$

Accepted: 25/08/2017

(c) BY The Author(s), 2018. Open Access. This article is distributed under the terms of the Creative Commons Attribution 4.0 International License (http://creativecommons.org/licenses/by/4.0/), which permits unrestricted use, distribution, and reproduction in any medium, provided you give appropriate credit to the original author(s) and the source, provide a link to the Creative Commons license, and indicate if changes were made. 